\title{
Rancang Bangun Mesin Pencacah Sampah Organik Rumah Tangga
}

\author{
Noviyanti Nugraha, Dany Septyangga Pratama, Sopan Sopian, Nicolaus Roberto \\ Jurusan Teknik Mesin, Fakultas Teknologi Industri, Itenas Bandung \\ Email: noviyanti.mesin.itenas@gmail.com
}

\begin{abstract}
ABSTRAK
Proses pemotongan sampah menjadi ukuran yang lebih kecil, dapat mempercepat proses pengomposan, sehingga diperlukan mesin yang mampu mencacah sampah organik sisa rumah tangga. Penelitian ini bertujuan untuk merancang, membuat serta menguji mesin pencacah organik yang mampu mencacah sisa sampah organik rumah tangga yang memiliki karakteristik basah dan alot, dengan minim polusi baik polusi pencemaran udara maupun polusi suara. Perancangan dan pembuatan meliputi komponen: poros, pisau tetap, pisau putar, rangka, casing, hopper, motor listrik serta sistem transmisi. Pengujian meliputi persentase sampah tercacah, kapasitas output hasil cacahan, dan pengujian tingkat polusi suara. Hasil perancangan dan pembuatan mesin pencacah sampah ini memiliki dimensi 490x455x950mm dengan pisau pencacah yang terdiri dari 12 pisau putar dan 3 pisau tetap, berukuran panjang $100 \mathrm{~mm}$ tebal $3 \mathrm{~mm}$. Transmisi daya menggunakan V-belt type A no 55 dan 2 buah pulley yaitu pulley berukuran 2 inch dan pulley berukuran 8 inch dengan masingmasing untuk satu alur. Daya motor listrik 1 Hp. Bahan poros ST-37 dengan panjang dan diameter $600 \mathrm{~mm}$ dan 22mm,. Dimensi hopper output 170x170mm dengan kemiringan $20^{\circ}$. Dimensi saringan $230 \times 380 \times 2,5 \mathrm{~mm}$ dengan lubang $\emptyset 3 \mathrm{~mm}$ dan lubang pembuangan air $\emptyset 25,4 \mathrm{~mm}$. Mampu mencacah sampah organik sisa rumah tangga hingga $90 \%$ tercacah dan kapasitas output sampah sebesar 70\%-80\%, Tingkat kebisingan maksimum $90 \mathrm{db}$, masih didalam batas yang distandarkan yaitu $94 \mathrm{db}$.
\end{abstract}

Kata Kunci: Sampah Organik, Mesin Pencacah Sampah, Kapasitas Cacahan 


\section{PENDAHULUAN}

Sampah organik yaitu suatu jenis sampah yang dapat membusuk, dan terurai. Contoh dari sampah organik seperti gambar 1 yaitu sisa makanan dari sayur-sayuran, daun-daun atau buah-buahan. Proses daur ulang merupakan salah satu cara menanggulangi masalah sampah tersebut. (Panji Nugroho, 2013).

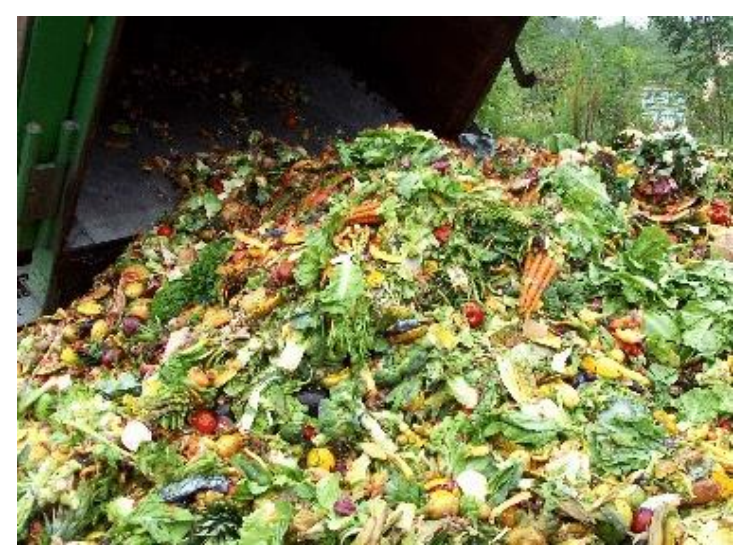

Gambar 1. Sampah organik.

Proses daur ulang adalah proses menjadikan bahan bekas atau sampah yang sudah tidak terpakai menjadi menjadi sesuatu yang baru yang dapat digunakan kembali dan memiliki nilai fungsi. (Jen Green, 2005). Dalam hal ini proses daur ulang adalah mengubah sampah organik sisa rumah tangga menjadi kompos. Kompos adalah hasil penguraian dari campuran bahan-bahan organik yang dapat dipercepat oleh populasi berbagai macam mikroba atau mikroorganisme dalam kondisi lingkungan yang hangat dan lembab (Sulistiyorini, 2011).

Proses pengomposan sampah organik akan lebih efisien apabila dilakukan sedekat mungkin dengan sumbernya dan skala kawasan misalnya kawasan pemukiman (RT/RW) dan kelurahan. Pengomposan sampah organik skala kawasan akan mengurangi biaya angkut dan biaya pembuangan sampah ke TPA (Subandrio dkk, 2012). Terdapat dua metode proses pengomposan yaitu aerob dimana proses pengomposan memerlukan oksigen, dan anaerob yaitu proses pengomposan tanpa oksigen (Sutanto, 2002).

Lamanya waktu yang diperlukan untuk proses pengomposan guna memperoleh kompos matang dan stabil tergantung pada beberapa faktor yaitu: rasio $\mathrm{C} / \mathrm{N}$ bahan dasar, ukuran partikel, keberadaan udara (keadaan aerobik), dan kelembaban (Jain dalam FAO, 1980). Proses pengomposan menggunakan mesin yaitu komposter dapat mempercepat waktu pengomposan (Noviyanti, 2017)

Dalam mempercepat proses pengolahan sampah menjadi kompos, berdasarkan faktor ukuran partikel sebaiknya sampah organik dicacah atau dipotong-potong terlebih dahulu sebelum dimasukan kedalam mesin komposter, sehingga dibutuhkan suatu alat atau mesin untuk memudahkan proses pencacahan tersebut yaitu mesin pencacah sampah organik. Mesin pencacah sampah organik berfungsi untuk memotong dan mencacah sampah menjadi potongan-potongan kecil sehingga memudahkan dalam proses pengomposan. Mesin pencacah sampah yang sudah 
ada pada umumnya terbatas, hanya untuk batang keras atau sampah organik harus dalam keadaan kering.

Pada penelitian ini akan dirancang serta dibuat mesin pencacah organik yang mampu mencacah sisa sampah organik rumah tangga yang umumnya dalam keadaan basah dan alot. Selain itu perancangan mesin pencacah organik ini diperuntukan untuk diletakan didekat perumahan sehingga dipilih jenis mesin yang minim menimbulkan polusi baik polusi pencemaran udara maupun polusi suara. Kemudian akan dilakukan pengujian terhadap hasil perancangan dan pembuatan yang meliputi pengujian persentase sampah tercacah, kapasitas output hasil cacahan, dan pengujian tingkat polusi suara.

\section{TINJAUAN PUSTAKA}

Prinsip kerja mesin pencacah sampah organik secara garis besar yaitu sampah organik dikumpulkan lalu dimasukan ke dalam mesin tersebut dan dicacah di dalam tabung pencacah dimana dalam tabung pencacah tersebut terdapat pisau putar dan pisau diam, setelah sampah tercacah maka sampah tersebut akan keluar di lubang output mesin pencacah dengan harapan sampah organik yang telah keluar memiliki ukuran yang lebih kecil agar memudahkan dalam proses pembuatan kompos.

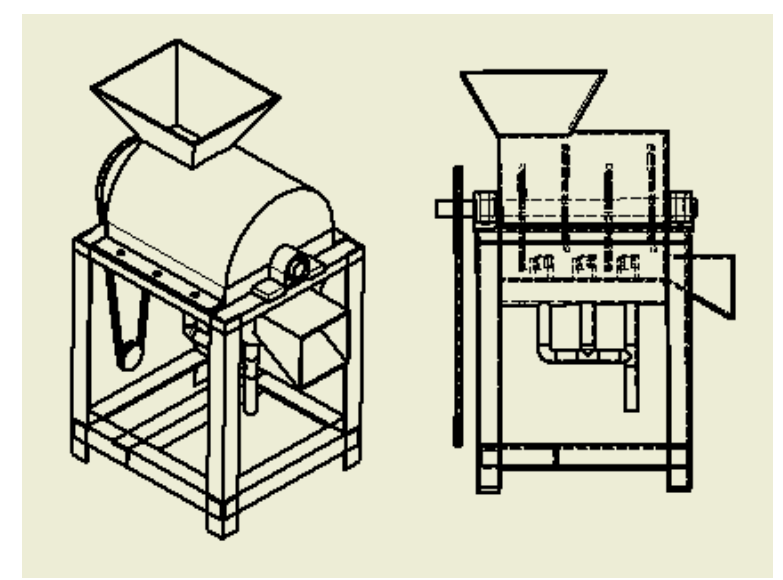

Gambar 2. Rancangan mesin pencacah sampah organik

Mesin pencacah sampah ini dirancang dengan mekanisme shredder dimana sampah yang dimasukan akan tertarik, terpotong, dan tercacah sehingga menjadi serpihan kecil. Mesin pencacah sampah ini menggunakan motor listrik sebagai daya utama dimana motor listrik ini berfungsi untuk memutarkan poros penggerak beserta pisau yang dihubungkan melalui pulley dan transmisi sabuk. Selain itu motor listrik memiliki tingkat polusi baik polusi udara maupun polusi suara, yang lebih kecil dibandingkan motor diesel.

Sebelum melakukan perancangan mesin pencacah, dibutuhkanlah kapasitas sampah yang akan diolah oleh mesin. Berdasarkan survey yang dilakukan di lingkungan masyarakat terdekat, sampah yang dihasilkan warga satu RT yaitu $30 \mathrm{~kg} / \mathrm{hari}-50 \mathrm{~kg} / \mathrm{hari}$ yang akan diproses dalam waktu 3 hari sekali dengan waktu pengoprasian mesin yaitu \pm 3 jam sehinga dalam sekali proses sampah total adalah $150 \mathrm{~kg}$. Maka kapasitas mesin yang dibutuhkan yaitu: $50 \mathrm{~kg} / \mathrm{jam}$. Dengan kapasitas sampah yang didapat yaitu $5 \mathrm{~kg}$. Berdasarkan data kapasitas sampah diperoleh dimensi tabung pencacah dengan ukuran diameter $300 \mathrm{~mm}$, dan panjang 400mm. Berdasarkan hasil 
perhitungan, daya penggerak yang dibutuhkan adalah 1Hp, dengan putaran dari motor listrik 1450 rpm direduksi menjadi $360 \mathrm{rpm}$ (Dany, 2018).

Komponen-komponen mesin pencacah yang dibuat yaitu poros penggerak pisau, dudukan pisau, pisau putar, pisau tetap, plat saringan air, hopper, rangka dan casing atau penutup mesin. Selain itu terdapat beberapa komponen yang telah tersedia di pasaran seperti motor listrik, transmisi sabuk (v-belt), pulley, pillow block dan bearing.

Berdasarkan hasil perhitungan diperoleh dimensi poros yaitu memiliki diameter $40 \mathrm{~mm}$ dan panjang $600 \mathrm{~mm}$ menggunakan material ST 37. Poros diberi lubang dengan ukuran panjang 10 $\mathrm{mm}$ lebar $20 \mathrm{~mm}$ dan kedalaman $10 \mathrm{~mm}$ untuk dudukan pisau pisau putar. Pada poros kemudian dipasang pisau putar dengan jumlah total 12 buah, masing masing 3 buah dipassangkan pada sekeliling poros pada jarak tertentu seperti yang terlihat pada gambar 3. (Sopan, 2016).

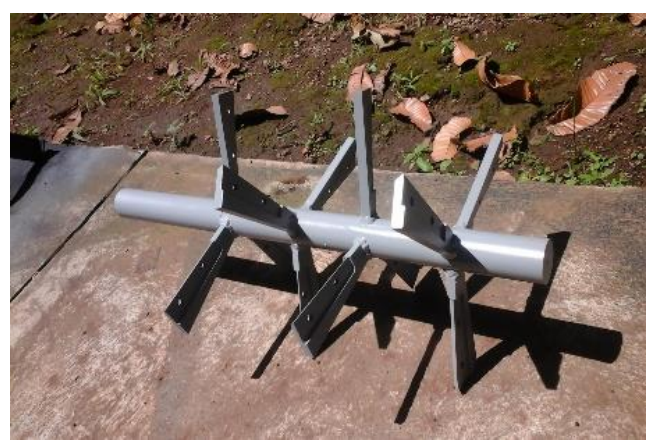

Gambar 3. Pisau putar yang terpasang pada poros

Pisau ini berfungsi sebagai komponen yang akan mencacah atau memotong sampah menjadi potongan-potongan kecil. Selain pisau putar yang menempel pada poros seperti gambar 3 diatas, ada pula jenis pisau yang lain yaitu pisau tetap yang dipasangkan pada dudukan pisau kemudian dudukan pisau dipasangkan pada pada plat saringan air.

Poros penggerak yang akan berputar mengikuti putaran motor listrik dimana pada kedua mata potong pisau ini akan saling bertemu, sehingga pada saat poros diputar dan sampah berada di dalam mesin, maka sampah akan terpotong sekaligus bergerak oleh mata pisau dan tercacah menjadi potongan-potongan kecil.

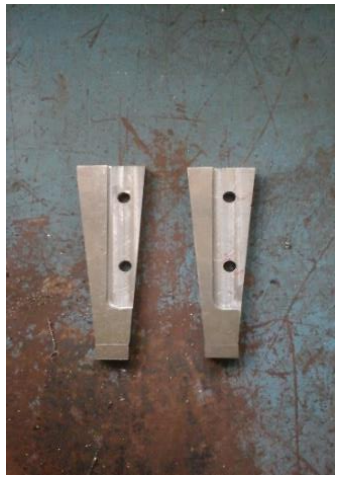

Gambar 4a. Pisau putar

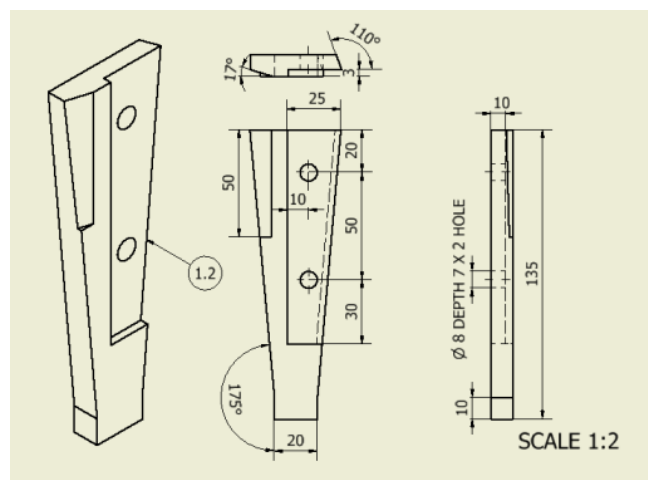

Gambar 4b. Dimensi pisau putar 
Bentuk pisau tetap dapat dilihat pada Gambar 4a. Dan ukuran pisau tetap dapat dilihat pada gambar 4b. Sedangkan pisau tetap berukuran panjang $100 \mathrm{~mm}$ tebal $3 \mathrm{~mm}$ yang ditempatkan pada dudukan pisau tetap yang berukuran panjang $230 \mathrm{~mm}$, lebar $30 \mathrm{~mm}$ dan tebal $3 \mathrm{~mm}$, seperti pada gambar 5 .

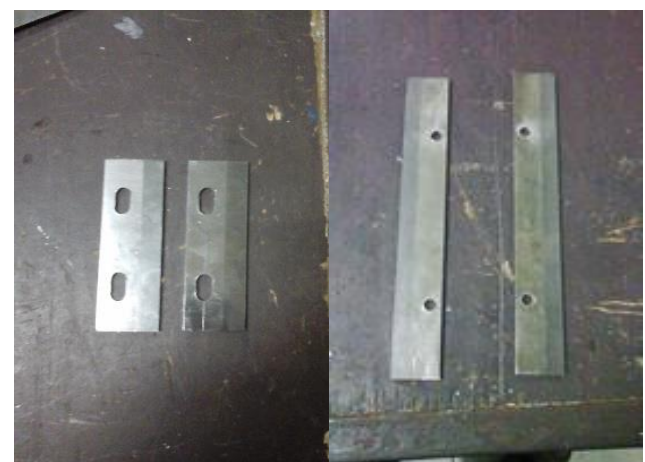

Gambar 5. Pisau tetap (kiri) dan dudukan pisau tetap (kanan)

Dudukan pisau tetap ditempelkan pada saringan berupa plat berlubang berukuran panjang dan lebar, 230x380 mm serta tebal 2,5mm, dengan lubang $\emptyset 3 \mathrm{~mm}$ seperti pada gambar 6. Pemasangan pisau dengan dudukan nya menggunakan mur dan baut agar mudah untuk perawatan pisau.

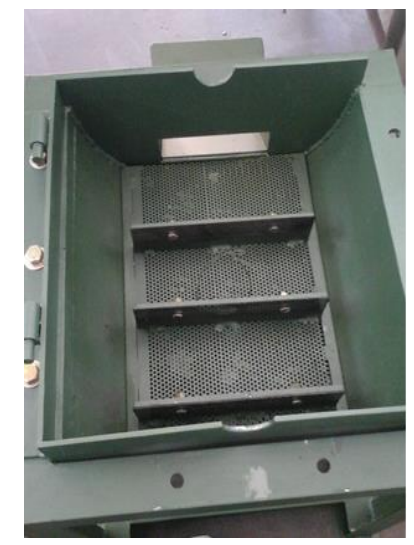

Gambar 6. Dudukan Pisau yang terpasang pada saringan dan casing bagian bawah

Gambar 6. Juga memperlihatkan saringan yang terpasang pada casing. Casing merupakan bagian komponen mesin pencacah sebagai rumah dari komponen utama, casing ini terdiri dari dua bagian yaitu cassing bagian atas dan cassing bagian bawah. Untuk casing bagian bawah yang berfungsi sebagai dudukan saringan dan terdapat lubang pembuangan air $\emptyset 25,4 \mathrm{~mm}$. Material casing berupa plat dengan tebal $5 \mathrm{~mm}$. Casing bagian atas diberi hopper input untuk memasukkan sampah yang akan dicacah. Hopper output dipasangkan pada bagian sisi casing bawah dengan ketebalan yang sama dengan casing yaitu 5mm. Hopper ouput memiliki panjang x lebar 170x170 $\mathrm{mm}$ dan dimiringkan dengan kemiringan $20^{\circ}$ seperti terlihat pada gambar 7 agar sampah yang tercacah bisa keluar dari hopper output (Sopan, 2016). 


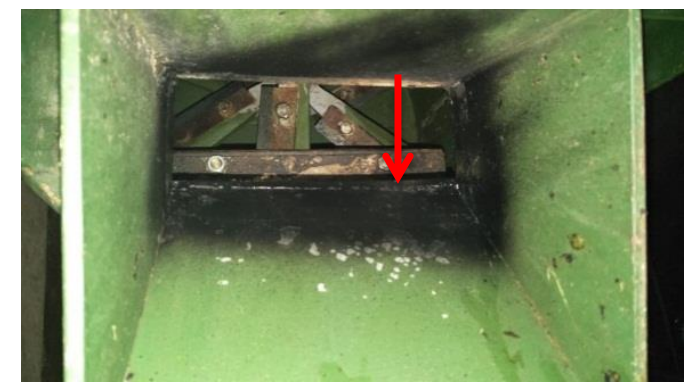

Gambar 7. Lubang Hopper output

Rangka seperti pada gambar 8 berfungsi sebagai rangka utama yang digunakan untuk dudukan motor listrik, pillow block, poros, pulley dan casing. Material rangka yaitu besi siku L. Kaki Rangka bagian depan yaitu panjang $630 \mathrm{~mm}$ dibuat lebih pendek dari kaki rangka bagian belakang yang memiliki panjang $680 \mathrm{~mm}$ sehingga ruang cacahan menjadi miring sekitar $10^{\circ}$.

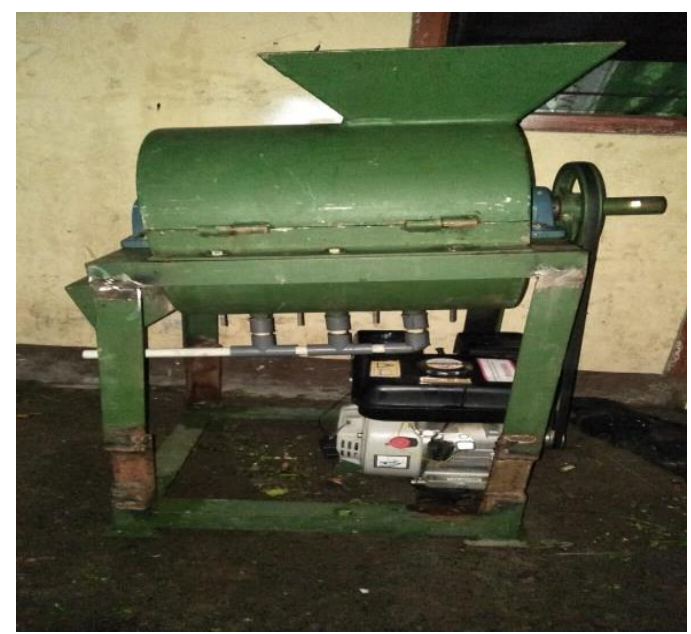

Gambar 8. Rangka mesin pencacah.

\section{HASIL DAN PEMBAHASAN}

Hasil pembuatan prototype mesin pencacah sampah ini, seperti yang telah dirancang sebelumnya memiliki dimensi $490 \times 455 \times 950 \mathrm{~mm}$ dengan pisau pencacah yang terdiri dari 12 pisau putar dan 3 pisau tetap, berukuran panjang $100 \mathrm{~mm}$ tebal $3 \mathrm{~mm}$ yang ditempatkan pada dudukan pisau tetap yang berukuran panjang $230 \mathrm{~mm}$, lebar $30 \mathrm{~mm}$ dan tebal $3 \mathrm{~mm}$. Daya motor listrik yang digunakan yaitu $1 \mathrm{hp}$, dengan putaran dari motor listrik $1450 \mathrm{rpm}$ direduksi menjadi $360 \mathrm{rpm}$. Transmisi daya menggunakan V-belt type A no 55 dan 2 buah pulley yaitu pulley berukuran 2 inch dan pulley berukuran 8 inch dengan masing-masing untuk satu alur. Panjang dan diameter poros adalah $600 \mathrm{~mm}$ dan $22 \mathrm{~mm}$, bahan poros ST-37. Dimensi hopper output 170x170mm dengan kemiringan $20^{\circ}$. Dimensi saringan $230 \times 380 \mathrm{~mm}$ serta tebal $2,5 \mathrm{~mm}$ dengan lubang $\varnothing 3 \mathrm{~mm}$ dan lubang pembuangan air $\emptyset 25,4 \mathrm{~mm}$. Gambar 9 dan gambar 10 memperlihatkan mesin pencacah yang telah dibuat, tampak bagian luar dab bagian dalam. 


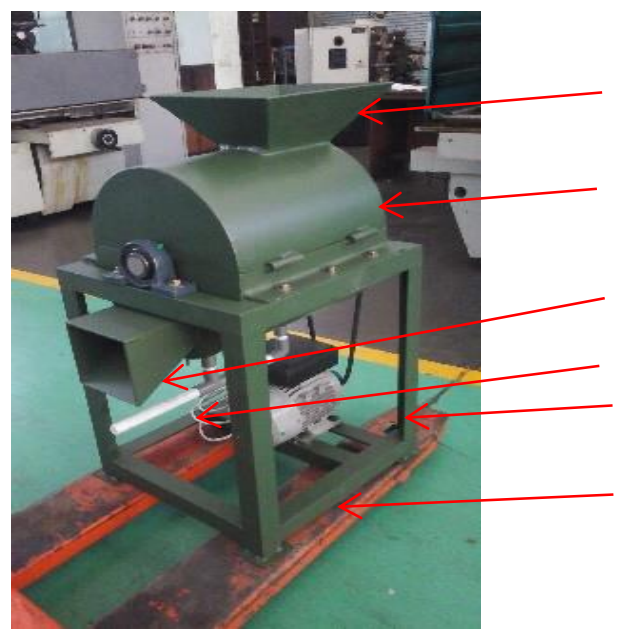

1 Hopper input

2 Cassing bag atas

3 Hopper output

4 Pipa air

5 Motor bensin

6 Rangka mesin

Gambar 9. Mesin pencacah sampah organik tampak luar

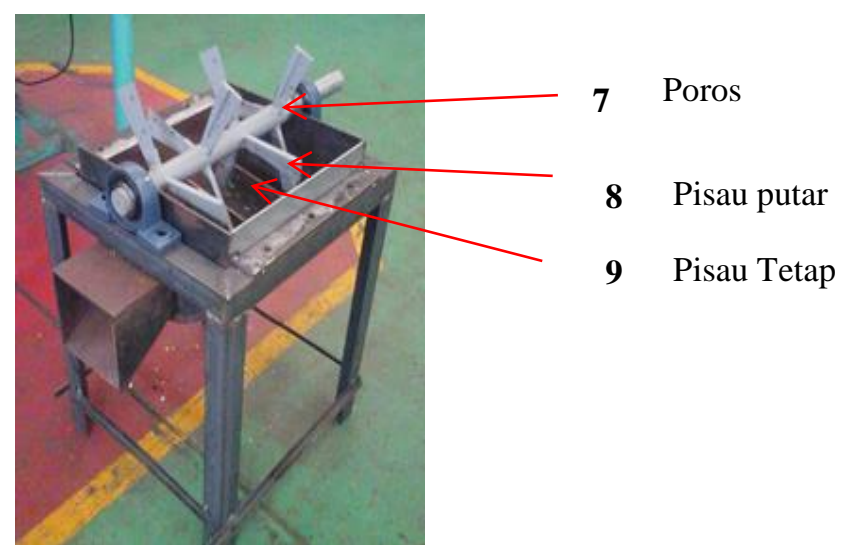

Gambar 10. Bagian dalam mesin pencacah organik

Setelah proses pembuatan mesin pencacah sampah organik selesai, dilakukan pengujian terhadap mesin tersebut. Parameter pengujian meliputi kapasitas hasil cacahan, persentase tercacah, diameter hasil cacahan, waktu cacahan dan tingkat kebisingan.

Prosedur pengujian adalah sebagai berikut, pertama sampah organik disiapkan kemudian ditimbang, massa sampah organik yang akan diproses disesuaikan dengan perancangan yaitu sebanyak $5 \mathrm{~kg}$. Setelah sampah yang akan diuji disiapkan, mesin pencacah sampah dihidupkan, sampah dimasukkan ke dalam hopper input untuk dicacah. Hasil cacahan akan keluar melalui hopper output Sampah yang telah keluar ditimbang. Hasil dari pengujian tersebut sampah tercacah $90 \%$ tetapi masih terdapat sampah yang tidak keluar dari hopper output sebesar 30\%. Artinya sampah kapasitas luaran sampah sebesar 70\%. Dimensi hasil cacahan kurang lebih sebesar diameter saringan yaitu kurang lebih $10 \mathrm{~mm}$. Hasil cacahan dapat terlihat pada gambar 11. 


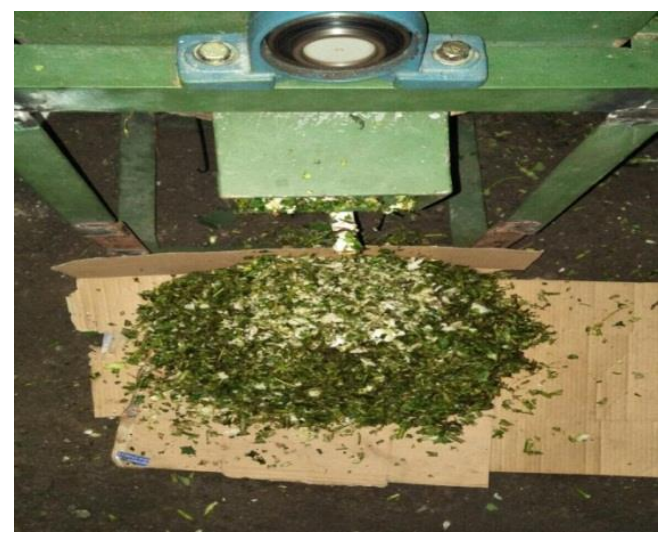

Gambar 11. Hasil cacahan

Pengujian selanjutnya dicoba memodifikasi mesin pencacah dengan menambahkan blower dengan spesifikasi; Diameter blower 2 inci, daya 150 Watt, tegangan 220 Volt, arus 1.0 ampere, kecepatan putar $3600 \mathrm{rpm}$. Blower dipasangkan pada bagian belakang mesin seperti pada gambar 12 (Nicolaus, 2018).

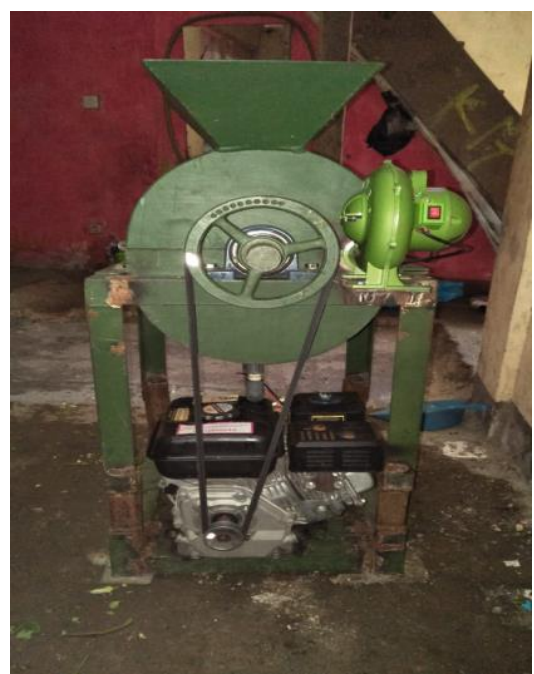

Gambar 12. Mesin pencacah yang ditambahkan blower

Setelah ditambahkan blower, kapasitas hasil cacahan meningkat menjadi $80 \%$. Kapasitas output hasil cacahan kurang maksimal karena diameter saluran keluaran terlalu kecil. Perlu dimodifikasi agar lubang keluaran menjadi lebih besar sekitar 5-10 mm. Data hasil pengujian untuk putaran yang berbeda-beda dapat dilihat pada tabel 1 .

Tabel 1. Data hasil pengujian mesin pencacah sampah organik

\begin{tabular}{|c|c|c|c|c|c|c|c|c|}
\hline No & $\begin{array}{l}\text { Massa } \\
\text { sampah } \\
\text { (kg) }\end{array}$ & $\begin{array}{l}\text { Presentase } \\
\text { tercacah } \\
(\%)\end{array}$ & $\begin{array}{l}\text { Presentase } \\
\text { keluar } \\
(\%)\end{array}$ & $\begin{array}{l}\text { Waktu } \\
\text { (min) }\end{array}$ & $\begin{array}{l}\text { Putaran } \\
\text { Motor } \\
\text { (Rpm) }\end{array}$ & $\begin{array}{l}\text { Putaran } \\
\text { Pisau } \\
(\text { Rpm) }\end{array}$ & $\begin{array}{l}\text { Tingkat } \\
\text { Kebisingan } \\
\text { (dB) }\end{array}$ & $\begin{array}{l}\text { Dimensi } \\
\text { cacahan } \\
(\mathrm{mm})\end{array}$ \\
\hline 1 & 5 & 90 & 80 & 60 & 2317 & 645,4 & 90,7 & 10 \\
\hline 2 & 5 & 90 & 80 & 60 & 2296 & 638,8 & 88,8 & 10 \\
\hline 3 & 5 & 90 & 80 & 60 & 2009 & 562,4 & 86,2 & 10 \\
\hline
\end{tabular}


Tingkat kebisingan yang ditimbulkan masih dibawah standar kebisingan yang diijinkan yaitu 94 desibel seperti yang diperlihatkan pada Tabel 2. Sumber standar : Pengukuran Standar Batas Tingkat Kebisingan dan Zona Kebisingan (Nicolaus, 2018).

Tabel 2. Standar tingkat kebisingan

\begin{tabular}{lll} 
No & $\begin{array}{l}\text { Tingkat } \\
\text { Kebisingan (dBA) }\end{array}$ & $\begin{array}{l}\text { Pemaparan } \\
\text { Harian }\end{array}$ \\
\hline $\mathbf{1}$ & 85 & 8 jam \\
\hline $\mathbf{2}$ & 88 & 4 jam \\
\hline $\mathbf{3}$ & 91 & 2 jam \\
\hline $\mathbf{4}$ & 94 & 1 jam \\
\hline $\mathbf{5}$ & 97 & 30 menit \\
\hline $\mathbf{6}$ & 100 & 15 enit \\
\hline
\end{tabular}

\section{KESIMPULAN}

Mesin pencacah sampah ini dirancang dengan mekanisme shredder dimana sampah yang dimasukan akan tertarik, terpotong, dan tercacah sehingga menjadi serpihan kecil, daya motor listrik yang digunakan sebesar $1 \mathrm{hp}$ dengan putaran dari motor listrik $1450 \mathrm{rpm}$ direduksi menjadi $360 \mathrm{rpm}$. Hasil pembuatan prototype mesin pencacah sampah ini, seperti yang telah dirancang sebelumnya memiliki dimensi $490 \times 455 \times 950 \mathrm{~mm}$ dengan pisau pencacah yang terdiri dari 12 pisau putar dan 3 pisau tetap, berukuran panjang 100mm tebal $3 \mathrm{~mm}$ yang ditempatkan pada dudukan pisau tetap yang berukuran panjang $230 \mathrm{~mm}$, lebar $30 \mathrm{~mm}$ dan tebal $3 \mathrm{~mm}$. Transmisi daya menggunakan $V$-belt type A no 55 dan 2 buah pulley yaitu pulley berukuran 2 inch dan pulley berukuran 8 inch dengan masing-masing untuk satu alur. Panjang dan diameter poros adalah $600 \mathrm{~mm}$ dan $22 \mathrm{~mm}$, bahan poros ST-37. Dimensi hopper output 170x170mm dengan kemiringan $20^{\circ}$. Dimensi saringan 230 x $380 \mathrm{~mm}$ serta tebal $2,5 \mathrm{~mm}$ dengan lubang $\emptyset 3 \mathrm{~mm}$ dan lubang pembuangan air $\varnothing 25,4 \mathrm{~mm}$. Mampu mencacah sampah organik sisa rumah tangga hingga $90 \%$ tercacah dan kapasitas output sampah sebesar 70\%, Jika ditambahkan blower kapasitas output sampah meningkat hingga 80\%. Tingkat kebisingan maksimum $90 \mathrm{db}$, masih didalam batas yang distandarkan yaitu $94 \mathrm{db}$.

\section{DAFTAR PUSTAKA}

[1] Panji Nugroho, 2013. Panduan Membuat Kompos Cair. Jakarta: Pustaka baru press

[2] Green Jen, 2005. Daur Ulang. Pakar Raya, Bandung

[3] Sulistyorini, lilis, 2011. Pengelolaan Sampah Dengan Cara Menjadikannya Kompos. Journal Unair. Diperoleh dari http://journal.unair.ac.id/download-fullpapers-KESLING-2-1-08.pdf [diakses 09/05/17]

[4] Subandriyo, Didi Dwi Anggoro, Hadiyanto, 2012. Optimasi Pengomposan Sampah Organik Rumah Tangga Menggunakan Kombinasi Aktivator EM4 Dan Mol Terhadap Rasio C/N. Jurnal Ilmu lingkungan UNDIP. Volume 10 Issue 2: 70-75(2012) ISSN 1829-8907.

[5] Sutanto, R. 2002. Pertanian Organik Menuju Pertanian Alternatif dan Berkelanjutan. Penerbit Kanisius. Yogyakarta

[6] Jain-FAO. 1980. Mechanized Compost Plant, Delhi. In Compost Technology. Project Field Document No. 13. 
[7] Noviyanti, Muhammad Ridwan, Nuha Desi A, Odi Fauzi, David Yusuf. 2018. Rancang Bangun Komposter Rumah Tangga Komunal Sebagai Solusi Pengolahan Sampah Mandiri Kelurahan Pasirjati Bandung. CR Journal vol 3 no 2 2017. BP2D Jawa barat.

[8] Dany Septyangga Pratama, 2018. Perancangan Mesin Pencacah Sampah Organik Sisa Rumah Tangga. Tugas Akhir Institut Teknologi. Nasional. Bandung

[9] Sopan Sopian, 2016. Pembuatan Mesin Pencacah Sampah Rumah Tangga. Tugas Akhir Institut Teknologi. Nasional. Bandung.

[10] Nicolaus Roberto. 2018. Pengujian Mesin Pencacah Sampah Organik Rumah Tangga. Tugas Akhir Institut Teknologi. Nasional. Bandung 